\title{
Expectativas e sentimentos de pais em relação ao bebê durante a gestação
}

\author{
Fathers' expectations and feelings regarding \\ their baby during pregnancy
}

\author{
Cesar Augusto PICCININI \\ Daniela Centenaro LEVANDOWSKI ${ }^{2}$ \\ Aline Grill GOMES \\ Daniela LINDENMEYER ${ }^{3}$ \\ Rita Sobreira LOPES
}

\begin{abstract}
Resumo
Conforme o referencial psicanalítico, a relação pai-bebê estabelecida durante o período gestacional, por meio da construção de uma imagem mental do bebê e da interação entre ambos, tem importante consequência para a relação pai-filho(a) após o nascimento. Assim, o objetivo deste estudo foi investigar as expectativas e os sentimentos de futuros pais em relação ao seu bebê. Participaram deste estudo 35 pais que esperavam seu primeiro filho, com idades entre 21 e 40 anos, e que viviam com a mãe do bebê. Os pais foram entrevistados individualmente em sua residência. A análise de conteúdo qualitativa das entrevistas revelou que poucos pais referiram dificuldades para imaginar o bebê. De forma geral, os pais já haviam construído uma imagem mental do bebê, incluindo suas características físicas e psicológicas, bem como o sexo. Além disso, haviam participado da escolha do nome e manifestaram preocupações quanto à saúde da criança.
\end{abstract}

Unitermos: Bebê. Gestação. Expectativas. Paternidade. Sentimentos.

\begin{abstract}
According to the psychoanalytical, theoretical framework, the father-infant relationship established during pregnancy, through the construction of a mental image of the infant and through father-infant interaction, has important consequences for the father-infant relationship after the birth. The aim of this study was to investigate the expectations and feelings of the father-to-be regarding his baby. Thirty-five first-time fathers, aged 21 to 40, who lived with the baby's mothers, participated in this study. The mothers were all primiparas. The fathers were interviewed individually at home. An analysis of qualitative content revealed that few fathers reported difficulties in imagining the baby. In general, they showed that they had already constructed a mental image of the baby, imagining its physical and psychological characteristics, as well as its sex. They also participated in the choice of the baby's name and expressed concerns as to the child's health.
\end{abstract}

Uniterms: Baby. Pregnancy. Expectations. Fatherhood. Emotions.

\section{$\nabla \nabla \nabla \nabla$}

1 Universidade Federal do Rio Grande do Sul, Instituto de Psicologia, Programa de Pós-Graduação em Psicologia. R. Ramiro Barcelos, 2600, Sala 111, 90035-003, Porto Alegre, RS, Brasil. Correspondência para/Correspondence to: C.A. PICCINNI. E-mail: <piccinini@portoweb.com.br>.

2 Universidade Federal de Ciências da Saúde, Departamento de Psicologia. Porto Alegre, RS, Brasil.

3 Psicóloga. Porto Alegre, RS, Brasil. 
A relação do pai e da mãe com seu filho(a) já começa desde antes do período pré-natal, e se dá, basicamente, a partir das expectativas que eles têm sobre o bebê ${ }^{4}$ e da interação que estabelecem com ele (Brazelton \& Cramer, 1992; Klaus \& Kennel, 1993; Piccinini, Gomes, Moreira \& Lopes, 2004a; Stainton, 1985). A imagem mental que cada membro do casal constrói a respeito do bebê, durante a gravidez, tem sua origem tanto em conteúdos inconscientes, representados pelas fantasias e desejos, como também em dados concretos já passíveis de serem conhecidos neste momento, como os movimentos fetais (Raphael-Leff, 1997).

Os pais tendem a nomear e atribuir características ao bebê antes mesmo do nascimento, como uma tentativa de tornar mais familiar este ser que já é tão íntimo e próximo, mas, ao mesmo tempo, ainda tão desconhecido (Szejer \& Stewart, 1997). A partir deste movimento de se aproximar e conhecer o bebê, esperar respostas dele e oferecer de antemão um modelo de interação, estabelece-se um padrão de relação mãe-bebê e pai-bebê. Para Bradley (2000), desde muito cedo este modelo relacional servirá como um importante precursor da relação da tríade pai-mãe-bebê após o nascimento.

Embora exista uma tradicional ênfase no estudo da relação gestante-bebê, algumas pesquisas têm destacado também a existência de uma relação específica pai-bebê ainda durante o período gestacional, estabelecida basicamente por meio da construção de uma imagem mental sobre o bebê, do exercício da paternidade e dos contatos interacionais entre ambos (Bornholdt, 2001; Levandowski \& Piccinini, 2006; Piccinini, Silva, Gonçalves, Lopes \& Tudge, 2004b).

Cramer e Palácio-Espasa (1993) entendem que as projeções e as expectativas de pais e mães em relação ao filho são muito semelhantes, apesar de as mulheres vivenciarem mais intensamente as transformações fisiológicas da gestação. Poder-se-ia pensar, então, que o conceito tradicional de bebê imaginário (Soulé, 1987), inicialmente formulado para explicar as expectativas e representações que a mãe constrói acerca do bebê, mesmo antes de seu nascimento e até de sua concepção (Szejer \& Stewart, 1997), esteja também presente no psiquismo do pai.

O pai, durante o período gestacional, pode desenvolver uma relação com o filho, ocupando seu lugar como pai, o que antes costumava acontecer somente com a gestante, uma vez que tradicionalmente o pai ficava encarregado de cuidar da companheira para que esta fosse capaz de proporcionar um bom ambiente ao bebê (Gomes \& Resende, 2004; Parke, 1996; Silveira, 1998). Atualmente, pelo menos em algumas culturas, como a norte-americana e a brasileira, parece que o pai também está se relacionando com o bebê de forma mais ativa, estabelecendo um contato mais direto com o mesmo já na gestação (Anderson, 1996; Piccinini et al., 2004b).

Entretanto, apesar desta tendência de inclusão cada vez maior do pai na vida do bebê, as diferenças entre maternidade e paternidade seguem existindo. A trajetória masculina rumo à parentalidade difere da feminina, pois somente a mulher pode sentir o filho crescer dentro de si, dar à luz e amamentá-lo. Por esta razão, de acordo com Maldonado, Dickstein e Nahoum (1997), alguns pais não conseguem criar um vínculo tão intenso e sólido com o bebê no período pré-natal. Para estes autores, a formação do vínculo entre pai e filho costuma ser mais lenta, consolidando-se gradualmente após o nascimento e ao longo do desenvolvimento da criança. Com isso, pode decorrer um sentimento de exclusão, comumente encontrado nos pais neste período (Anderson, 1996; Bornholdt, 2001).

Além disso, durante a gestação muitos pais não sabem como interagir, como entrar em contato com seus bebês e estabelecer com eles uma relação. Shapiro (1987) ressaltou que, ainda que hoje os homens desejem e possam participar mais do processo da gravidez, eles, em sua maioria, não tiveram modelos de pais participativos. Soma-se a isto o fato de que nem todos os pais conseguem se sentir envolvidos com o bebê durante o período gestacional (Bornholdt, 2001). Contribuiria, para que isso acontecesse, o resgate de aspectos

\footnotetext{
4 Embora este estudo trate do período da gestação e, portanto, refira-se ao feto, o termo "bebê" foi usado em grande parte do texto por parecer mais adequado ao se referir ao significado que o pai atribui ao filho. Feto é predominantemente utilizado na literatura médica e parece não representar adequadamente os sentimentos que envolvem a representação de um filho. Porém, em algumas situações, fez-se necessário recorrer a esta terminologia, para não confundir o leitor.
} 
decorrentes da identificação feminina, geralmente com a própria mãe, que, se integrados na consolidação da masculinidade, poderiam levar os pais a uma maior empatia tanto com a esposa quanto com o bebê (Brazelton \& Cramer, 1992; Raphael-Leff, 1997). Isso aconteceria quando o pai conseguisse se conectar psiquicamente com os cuidados de maternagem recebidos na sua infância, podendo, assim, utilizá-los para se vincular e cuidar do filho.

Diversos autores têm sugerido algumas estratégias que facilitariam ao pai estar em contato com seu bebê durante o período pré-natal. Uma delas seria através do contato tátil com a pele da barriga da gestante, isto é, favorecer ao pai experienciar a resposta dos movimentos fetais, podendo, desta forma, também sentir o bebê e, com isso, construir uma imagem mental dele (Raphael-Leff, 1997). A ultrassonografia também tem sido considerada um outro recurso facilitador da inclusão dos pais no processo gestacional, uma vez que partilham uma posição de igualdade com a mãe no momento do exame, pois ambos enxergam a mesma imagem do bebê e têm acesso às mesmas informações (Piontelli, 2000). Segundo essa autora, a partir desta visualização os futuros pais tendem a se sentir mais responsáveis pelos cuidados com a mãe e o bebê.

Essas formas diretas de interação podem contribuir para que o pai construa uma imagem mental de seu filho, permitindo que ele tenha o bebê no seu mundo psíquico desde a gestação, como acontece em geral com a gestante. Nesse sentido, Piccinini et al. (2004a), com base em entrevistas com 39 gestantes primíparas, confirmaram que desde a gestação a mulher se dedica à construção de um "lugar" psíquico para o seu bebê. Nos relatos das participantes daquele estudo, ficou clara a existência de uma relação materno-fetal bastante intensa, embasada especialmente nos sentimentos e/ou expectativas das gestantes sobre o sexo, o nome, as características psicológicas, a interação com o feto e as preocupações com a saúde dele.

À semelhança das mães, muitos são os aspectos sobre os quais os pais podem imaginar os filhos, como o sexo do bebê, as características físicas, o tempe- ramento, entre outros. O bebê anuncia, então, sua existência no psiquismo dos pais muito antes do seu nascimento, e os projetos e expectativas que envolvem a sua chegada preparam o lugar para acolhê-lo. Os aspectos concernentes a estas expectativas são diversos e é preciso compreendê-los, pois são palavras que preparam o espaço do bebê e, portanto, influenciam a relação pai-filho(a) após o nascimento (Szejer \& Stewart, 1997).

Contudo, apesar da relevância de se compreender o bebê que vai se constituindo no psiquismo do pai, a maioria dos estudos tem sido direcionados unicamente às gestantes. Assim, o objetivo deste estudo foi investigar as expectativas e os sentimentos de futuros pais em relação ao seu bebê durante o processo gestacional.

\section{Método}

\section{Participantes}

Participaram deste estudo 35 pais que esperavam seu primeiro filho(a) ${ }^{5}$, com idades entre 21 e 40 anos (Média - M=30,3 anos; desvio-padrão - DP=5,42). Todos viviam com as gestantes, que não apresentaram problemas de saúde durante a gestação. Os participantes eram de níveis socioeconômicos variados e residiam na região metropolitana de Porto Alegre, Rio Grande do Sul, Brasil. Com relação ao nível de escolaridade, os pais tinham ensino fundamental incompleto (9\%) ou completo (12\%); ensino médio incompleto (3\%) ou completo (22\%); ensino superior incompleto (28\%) ou completo (16\%) e, alguns, pós-graduação (9\%). A classificação da ocupação dos pais foi realizada com base na escala ocupacional de Hollingshead (1975), adaptada para este estudo. As ocupações foram distribuídas em nove categorias; 34\% dos pais tinham ocupações classificadas nos níveis 1 a 4, correspondentes ao status socioeconômico baixo; 26\% tinham ocupações de níveis 5 e 6; e 23\% tinham ocupações de níveis 7 a 9, correspondentes ao status socioeconômico elevado.

$\boldsymbol{\nabla \nabla \nabla v}$

s A amostra foi selecionada dentre os participantes do Estudo longitudinal de Porto Alegre: da gestação à escola - ELPA (Piccinini, Lopes, Sperb \& Tudge, 1998). 


\section{Procedimentos}

O contato inicial para participar do estudo foi feito com as gestantes: os objetivos do estudo eram explicados a elas e seus maridos eram convidados a participar. Aqueles que concordaram, preencheram a Ficha de Contato Inicial (Grupo de Interação Social, Desenvolvimento e Psicologia - GIDEP, 1998a). Posteriormente, foi feito um contato telefônico, para marcar uma visita à residência dos participantes, e a coleta de dados foi iniciada mediante assinatura do Termo de Consentimento Livre e Esclarecido. Após isso, realizou-se a Entrevista de Dados Demográficos do Casal (GIDEP, 1998b), com o objetivo de obter informações demográficas adicionais, como idade, escolaridade, estado civil, ocupação, religião e grupo étnico do pai e da gestante. Em seguida, foi solicitado ao pai que respondesse à Entrevista Sobre a Gestação e as Expectativas do Futuro Pai (GIDEP, 1998c). Esta entrevista semiestruturada envolveu vários blocos de questões, que investigaram diversos temas relacionados à vivência da gravidez, às expectativas e sentimentos sobre o bebê, à relação pai-bebê, à relação conjugal, às vivências na família de origem e à percepção sobre a companheira. Foram examinados apenas os relatos dos pais a respeito de suas expectativas e sentimentos sobre o bebê no período gestacional.

\section{Resultados}

As respostas dos futuros pais à entrevista foram analisadas por meio de análise de conteúdo qualitativa (Bardin, 1977; Laville \& Dione, 1999). Com base na literatura (Brazelton \& Cramer, 1992; Klaus \& Kennell, 1993; Piccinini et al., 2004a; Raphael-Leff, 1997) e nas respostas dos participantes, foram criadas cinco categorias temáticas envolvendo as expectativas e sentimentos paternos quanto: 1) ao sexo do bebê; 2) ao nome do bebê; 3) às características físicas do bebê; 4) às características psicológicas do bebê; e 5) à saúde do bebê. Além disso, dentro de cada categoria foram criadas subcategorias, descritas abaixo. Dois pesquisadores independentes classificaram separadamente os relatos dos futuros pais em cada uma das categorias e subcategorias e, em casos juiz. Apresenta-se, a seguir, a caracterização das categorias e subcategorias, exemplificando-as com verbalizações dos próprios pais (Tabela 1).

\section{Quanto ao sexo do bebê}

Esta categoria refere-se às expectativas e desejos que os pais expressaram quanto ao sexo do bebê, bem como suas implicações na relação pai-bebê. Os relatos dos pais foram classificados em três subcategorias: 1) expectativas quanto ao sexo do bebê; 2) desejo quanto ao sexo do bebê; e 3) implicações do sexo para os sentimentos do pai e seu relacionamento com o bebê.

Enquanto alguns pais revelaram uma expectativa definida de que o bebê seria de determinado sexo: "ah, a minha expectativa era de que fosse um guri", outros afirmaram não ter uma expectativa definida: "eu na verdade fui o que menos queria dar palpites disso, podia sermenino ou menina".

O desejo quanto ao sexo do bebê apareceu tanto relacionado às expectativas do próprio pai: "ah, eu tinha preferência de uma menina... toda vezqueeu ia em festa de quinze anos assim, eu olhava o pai dançando com a filha ... a valsa dos quinze anos e eu achava emocionante aquilo ali, e não sei, eu acho que é por causa disso", quanto às da gestante: "ela esperava uma menina, eu por mim não tinha... era indiferente o sexo, mas como ela queria tanto, eu até gostei mais". Um sentimento de imparcialidade também foi encontrado nos relatos dos pais, refletindo uma necessidade de não ter e/ou não revelar desejos quanto ao sexo do bebê: "eu tava imparcial ... lá dentro da barriga quietinha, no cantinho dela, ela estaria sentindo, eu acho, a minha preferência, então, eu procurei sempre ser imparcial, deixar pra que Deus decidisse. Oque vinha, vinhabem".

Quanto às implicações do sexo do bebê para a relação pai-bebê, os pais fizeram referência ao papel e/ou lugar que o bebê, por ser de determinado sexo, ocuparia na família: "preferência não só minha, mas da casa toda, era pra que fosse uma menina, não sei se por causa da [minha] mãe que [tinha] três filhos homens. Cada um que nascia ela ia dizer que era uma menina, uma menina, e era só homem". Os pais também relataram que 
Tabela 1. Porcentagem de ocorrências por categoria e subcategoria $(n=35)$.

\begin{tabular}{|c|c|c|c|}
\hline Categoria & Ocorrência & $n$ & $\%$ \\
\hline \multicolumn{4}{|l|}{ Quanto ao sexo do bebê } \\
\hline \multirow[t]{2}{*}{ Expectativas quanto ao sexo } & Expectativas definidas & 43 & 15 \\
\hline & Sem expectativas definidas & 6 & 2 \\
\hline \multirow[t]{3}{*}{ Desejos quanto ao sexo } & Relacionado ao próprio pai & 49 & 17 \\
\hline & Imparcialidade & 14 & 5 \\
\hline & Relacionados à gestante & 9 & 3 \\
\hline \multirow[t]{4}{*}{ Implicações do sexo } & Diferenciação nas práticas educativas & 23 & 8 \\
\hline & Identificação por ser do mesmo sexo & 14 & 5 \\
\hline & Papel/lugar na família & 9 & 3 \\
\hline & Sentimento de exclusão & 3 & 1 \\
\hline \multicolumn{4}{|l|}{ Quanto ao nome do bebê } \\
\hline Características do próprio nome & & 37 & 13 \\
\hline Pelo que o nome representa & & 34 & 12 \\
\hline Não referiram & & 28 & 10 \\
\hline \multicolumn{4}{|l|}{ Quanto às características físicas do bebê } \\
\hline Relacionadas aos genitores & & 71 & 25 \\
\hline Relacionadas ao desejo do pai & & 26 & 9 \\
\hline Não referiram & & 17 & 6 \\
\hline \multicolumn{4}{|c|}{ Quanto às características psicológicas do bebê } \\
\hline Relacionadas aos genitores & & 71 & 25 \\
\hline Relacionadas ao desejo do pai & & 20 & 7 \\
\hline Relacionadas a informações concretas & & 17 & 6 \\
\hline Não referiram & & 11 & 4 \\
\hline \multicolumn{4}{|l|}{ Quanto à saúde do bebê } \\
\hline Gerais & & 49 & 17 \\
\hline Específicas & & 20 & 17 \\
\hline Tranquilo pelo pré-natal & & 40 & 14 \\
\hline Culpa/medo & & 6 & 2 \\
\hline Referiu não ter preocupações & & 17 & 6 \\
\hline
\end{tabular}

Cada futuro pai pode ter dado respostas classificadas em mais de uma categoria.

a correspondência do sexo do bebê com um genitor poderia acarretar semelhanças psicológicas e comportamentais entre eles: "a vontade é aquela coisa, bah, às vezes fico imaginando ir para pescaria, para um jogo de futebol, coisa assim claro que o menino... claro que a menina vai acompanhar mais a mãe". Foi ainda evidenciado um sentimento de exclusão pelos pais, ao entenderem que o sexo do bebê poderia tornar a relação mãe-bebê mais próxima: "ah, minha expectativa era de quefosse um guri [menino] ... eupensei, quejudiaria, não é um guri, perdi a bebê pra ela". Por fim, o sexo do bebê também foi considerado um fator que diferenciaria as práticas educativas em relação ao bebê: "o guri tu pega, tu sacode, e a guriajáémais dengosa, não entendo porque, acho que é do convívio ali, que a guriazinha tem que ser calminha".
Como pode ser observado na Tabela 1, em relação à expectativa quanto ao sexo do bebê, a maioria dos futuros pais tinha uma expectativa definida de que o bebê seria de determinado sexo (43\%), seguida de alguns que não manifestaram uma expectativa específica sobre o sexo do bebê (6\%). Quanto ao desejo de o bebê ser de determinado sexo, um número expressivo de futuros pais (49\%) referiu suas próprias preferências por um dos sexos, enquanto 9\% relacionaram seu desejo ao desejo da gestante e 14\% revelaram-se imparciais. As implicações do sexo do bebê nos sentimentos dos futuros pais e na futura relação com ele apareceram mais ligadas à diferenciação das práticas educativas (23\%), seguida da identificação por ser do mesmo sexo (14\%), do papel/lugar que o bebê ocuparia na família (9\%) e do sentimento de exclusão (3\%). 


\section{Quanto ao nome do bebê}

Esta categoria incluiu aspectos que envolveram a escolha do nome do bebê. Os relatos dos participantes foram agrupados em duas subcategorias relacionadas às razões para a escolha: características do próprio nome e oque o nomelembra/aque remete.

Dentre as razões, destacaram-se as características do nome (comum, diferente, curto, antigo): "eu escolhi de um livro. Eu não queria um nome que ... pudesse ficar abreviado, um apelido para um nomelongo.... Éum nome bem a ver com os tempos que a gente tá vivendo agora, um nome bem brasileiro. Eleéum nome... quase de vogais, só uma consoante", e o que o nome lembrava: "eu acho que soa bem, ... eu não sei, talvez eu associe que quando eu morava em C., tinha um senhorque tinha um armazém ...e eu incomodei ele a adolescência inteira, a minha infância inteira. Então talvez eu queira me retratar, mas não sei".

Como se pode observar na Tabela 1, as expectativas e sentimentos da maioria dos futuros pais em relação ao nome do bebê apareceram ligados às características do próprio nome (37\%), seguidos pelo que este Ihes lembrava ou a que remetia (34\%).

\section{Quanto às características físicas do bebê}

Nesta categoria foram agrupadas as expectativas, impressões e desejos dos pais quanto às características físicas imaginadas para o bebê. Estas apareceram relacionadas tanto aos genitores, ou seja, ser parecido ou diferente do pai e/ou da mãe, quanto a como os pais queriam que o bebê fosse. Alguns pais não referiram uma imagem mental formada sobre o bebê.

Os pais indicaram características físicas do bebê relacionadas aos genitores - a um deles ou a uma combinação de características dos dois: "ela vai ter a pele mais oumenos morena como eu, ocabelo escuro, que nem odela, assim, bem cabeludinha, bem cabeludinha. Acho que vai ser assim, o narizinho parecido com o meu". As impressões quanto aos aspectos físicos do bebê também foram embasadas em como os pais queriam que o bebê fosse: "os olhos, os olhos eu espero que saiam parecidos com os do meu pai, ele tem ol hos verdes, que nasça com os ol hos verdes do vô". Além disso, alguns pais não relataram uma imagem mental sobre o bebê: "não consigo imaginar, não tenho ideia.
A maioria dos pais (Tabela 1) relatou que as características físicas do bebê estariam relacionadas à aparência dos genitores (71\%) e à ideia de que elas estariam de acordo com o desejo do pai (26\%). Alguns pais (17\%) não referiram expectativas quanto às características físicas dos bebês.

\section{Quanto às características psicológicas do bebê}

Esta categoria refere-se às impressões e desejos quanto às características psicológicas imaginadas para o bebê. As respostas dos pais foram classificadas em quatro subcategorias: relacionadas aos genitores, às informações concretas sobre o bebê, aos desejos e dificuldades de imaginar.

Os pais expressaram que o bebê teria características psicológicas semelhantes ou diferentes de um dos genitores ou de ambos: "o jeito acho que um pouco do pai, um pouco da mãe. Ela vai ser, acho que muito carinhosa, também muito brava". Imaginaram ainda as características psicológicas a partir de informações concretas sobre o bebê, como os movimentos fetais, e/ou pela observação na ultrassonografia: "vai ser arteiro, espoleta, porque na barriga ele já pula a noite toda". O desejo dos pais também serviu de base para que construíssem uma imagem mental sobre as características psicológicas do bebê: "tomara que seja tranquilo, calmo, inteligente, ativo, esportista"; "eu quero que ela seja bem calminha, eu gostaria que fosse bem calminha".Também alguns pais referiram não haver pensado sobre as características psicológicas do bebê: "o temperamento dela... eu nãopenseisobreisso".

A maioria dos pais (Tabela 1) esperava que as características psicológicas do bebê fossem semelhantes às dos genitores (71\%). Em segundo lugar, apareceram os relatos de que seus desejos seriam um fator de grande influência na determinação das características psicológicas do bebê (20\%), seguido do relato daqueles pais (17\%) que relacionaram suas expectativas com informações concretas sobre o bebê, baseadas especialmente no tipo de movimentos fetais e/ou nas imagens ultrassonográficas. Um número menor de pais (11\%) não referiu quaisquer ideias acerca de como seriam as características psicológicas do bebê. 


\section{Quanto à saúde do bebê}

Nesta categoria foram incluídas as preocupações dos futuros pais com relação ao bebê e à sua saúde, e a forma pela qual eles se tranquilizavam quanto às suas próprias ansiedades. Os relatos dos pais foram classificados em quatro subcategorias, denominadas: 1) preocupações em relação ao bebê; 2) culpa e medo; 3) tranquilização por meio do pré-natal; e 4) não referir preocupações.

Quanto à saúde do bebê, foram também relatadas tanto preocupações gerais: "eu acho que eu estou sempre acreditando que tudo vai correr bem, mas obviamente como pai não deixo de ter as minhas preocupações, que eu só vou ter a tranquilidade quando eu estiver [com ela] no colo, ver que está tudo OK"; como específicas, em particular com relação a malformações: "eu diria, em termos de percentual, eu tenho uma tranquilidade de $89 \%$. Devezem quando, como todo ser humano, seráque elevai ser... não ter perigo de nascer com Síndrome de Down"; e prematuridade: "a gente não quer que ele nasça atéo final do mês, depois aí sim tá tranquilo, daí não tem problema nenhum, pode até nascer. É que o ideal tem que ficar, até para a própria criança, ficar porvolta de trinta e seis a trinta eoito semanas com a mãe, na barriga". O sentimento de culpa ou medo de ter causado algum mal ao bebê também foi referido pelos pais: "tivemos preocupações no começo, que ela tava com sangramento, a gente até transou uma época e eu achei que, de repente, tivesse feito alguma coisa". No entanto, os recursos do acompanhamento pré-natal apareceram como uma forma de tranquilizar os pais quanto à saúde do bebê e/ou da gestante: "deu tudo bem nos exames, não deu nenhum problema, graças a Deus". Por fim, alguns pais referiram não ter preocupações quanto à saúde do bebê: "saúde também, sempre tive uma confiança, assim, de que vaiser perfeito"; "não, eu penso tudo o melhor, não penso que de repente possa acontecer alguma coisa, eu penso que vai dar tudo certo".

A Tabela 1 revela que muitos pais manifestaram preocupações tanto gerais (49\%) quanto específicas (20\%) em relação à saúde do bebê. Os recursos de diagnóstico pré-natal foram citados por muitos pais (40\%) por terem contribuído para reduzir suas preocupações. Alguns pais (6\%) também relataram culpa e/ou medo de causar algum dano à saúde do bebê (6\%), enquanto outros referiram não ter preocupações (17\%).

\section{Discussão}

Os resultados deste estudo revelaram que a grande maioria dos pais demonstrou já haver construído, até aquele momento da gestação, uma imagem mental sobre o seu bebê, incluindo suas características físicas e psicológicas e o sexo, assim como manifestado preocupações com a sua saúde e auxiliado na escolha do seu nome. Contudo, houve exceções: alguns não relataram a construção de uma imagem mental do bebê.

Conforme Piccinini et al. (2004a) constataram, imaginar características do bebê auxilia na construção de uma identidade para ele, tornando-o mais real e conhecido no psiquismo dos pais. Segundo os dados aqui obtidos, uma das formas utilizadas pelos pais para personificar o bebê foi a escolha do nome, que refletiu preferências, lembranças e modelos positivos desejados para o bebê. Além disso, imaginar o sexo do bebê e demonstrar uma preferência clara por um dos sexos foi uma forma de os pais se incluírem no processo gestacional, favorecendo uma maior familiaridade entre pai e bebê. Imaginar suas características físicas e psicológicas também serviu a este exercício. Enquanto alguns pais reconheceram que o bebê poderia ser mais parecido com o pai, ou com a mãe, outros enfatizaram características de ambos, como uma mescla, um produto dos dois genitores. Também as manifestações de preocupações em relação à saúde do bebê, dependendo de sua natureza (mais tranquilas ou mais ansiosas) pareceram contribuir para a construção de uma determinada imagem mental do bebê.

A partir do momento em que o bebê se torna mais concreto e conhecido para os pais, isso também facilita uma comparação com as famílias de origem do casal e, desta forma, propicia eventualmente a resolução de conflitos dos pais com os seus próprios genitores, apesar de também poder intensificá-los. Dentro dessa perspectiva, Cramer e Palacio-Espasa (1993) defenderam que a espera de um filho, embora seja um momento de possíveis crises emocionais, representa também uma possibilidade de amadurecimento relacional e psíquico. Desta forma, poder-se-ia pensar que o fato de imaginar o bebê, investindo nele(a) expectativas e desejos para dar "corpo" a esta imagem, tenderia a tornar o bebê mais conhecido e, portanto, mais comparável a perso- 
nagens da história passada dos pais, permitindo, no mínimo, a confrontação e a consequente possibilidade de reformulação de conflitos anteriores (Anderson, 1996; Brazelton \& Cramer, 1992; Riesch, Kuester, Brost \& McCarty, 1996; Slade \& Cohen, 1996).

É importante salientar que as expectativas e os sentimentos dos pais sobre o bebê foram baseados em diversas fontes, tais como seus próprios desejos e os dados concretos conhecidos sobre o feto, com base no acompanhamento pré-natal. No entanto, fica-se sem saber se os pais conseguiram conciliar os diferentes aspectos que influenciam a construção da imagem mental do bebê. É provável que alguns pais tenham privilegiado mais seus desejos em detrimento de informações concretas, ou vice-versa. De qualquer forma, de acordo com Cramer e Palácio-Espasa (1993), esta situação de conciliação seria mais saudável, pois no momento em que os desejos tomam conta do espaço destinado à individualidade do bebê, poder-se-ia organizar uma condição alienante na relação, envolvendo ameaças à emergência do selfverdadeiro do bebê.

Acredita-se que todo este movimento imaginativo dos pais, que ocorre durante a gestação, influencie a futura relação pai-bebê, repercutindo nas fantasias e representações paternas e na forma de interpretação dos sinais do bebê. Aqui, vale lembrar que alguns recursos pareceram auxiliar os pais neste processo imaginativo. A ultrassonografia foi referida por eles como um meio importante para imaginar o bebê, servindo como um estímulo para as suas fantasias. Para as mães, outros recursos estão disponíveis, especialmente a percepção constante dos movimentos fetais e sensações internas. Já para os pais, os recursos de acesso à criança são escassos e menos diretos. Por isso, a ultrassonografia pode ser entendida como um momento de igualdade entre o casal no acesso ao bebê (Piontelli, 2000), uma forma de tornar a gravidez mais real para os pais (Clement, Wilson \& Sikorski, 1998; Parke, 1996; Sullivan-Lyons, 1998).

Pode-se supor que os pais que evidenciaram já terem construído uma imagem mental do bebê representem uma tendência atual de maior participação na gestação e nos cuidados dos filhos, por já se mostrarem envolvidos com o filho mesmo antes de seu nascimento. Percebe-se que os pais têm sido chamados a ocupar um espaço mais expressivo na família, de modo bastante diferente do que os homens de forma geral faziam em tempos passados (Cabrera, Tamis-LeMonda, Bradley, Hofferth \& Lamb, 2000; Lewis \& Dessen, 1999; Parke, 1996).

Como comentado anteriormente, os pais, pela sua condição biológica, costumam se sentir excluídos do processo gestacional e, consequentemente, da interação com o bebê (Soulé, 1987). Tal condição biológica parece ter sido por muito tempo reforçada por condições sociais, que também levavam à participação indireta do pai nesse processo, quando não à sua exclusão (Bornholdt, 2001, 2006). Essa condição de exclusão poderia servir para o pai definitivamente se distanciar do processo, o que não parece ter acontecido com muitos participantes deste estudo, que se mostraram conectados ao bebê através das imagens construídas sobre ele. Para alguns autores, é necessário que os pais recorram às identificações de cuidado e maternagem que tiveram com sua própria mãe no passado, para que possam se incluir de fato no processo gestacional e se relacionar mais com o bebê (Brazelton \& Cramer, 1992; Raphael-Leff, 1997; Stern, 1997). Isto poderia estar ocorrendo com alguns pais deste estudo, especialmente aqueles que manifestaram características imaginadas para o bebê.

Essa condição poderia também estar ocorrendo em função de uma postura mais permissiva das próprias gestantes, que pode facilitar a entrada do pai no processo gestacional. Quando isto ocorre, abre-se uma possibilidade de aproximação dos pais em relação ao bebê, com uma vivência mais direta da gestação. Tal contato mobiliza sentimentos e conteúdos inconscientes dos pais. Nesse sentido, Cramer e Palácio-Espasa (1993) postularam que as projeções inconscientes dos pais em relação ao bebê podem ser de natureza tão primitiva quanto às das mulheres. Contudo, isto ocorreria somente entre pais que demonstrassem um nível de envolvimento mais profundo com a gestante e o bebê. Essa concordância é percebida se compararmos os dados do estudo aqui descrito com aqueles encontrados por Piccinini et al. (2004a), que investigaram a imagem mental do bebê por parte das gestantes. Nas duas pesquisas foram referidas fantasias, expectativas e projeções em relação ao bebê, envolvendo os mesmos aspectos (nome, sexo, características físicas e psicológicas e preocupações em relação à saúde) . Contudo, a não referência direta à construção da imagem mental 
do bebê apareceu de forma mais expressiva entre os pais do que entre as mães do estudo referido.

Cabe ressaltar, entretanto, que o fato de alguns pais não referirem explicitamente a construção de uma imagem mental do bebê não significa obrigatoriamente que não a tivessem construído internamente; pode ser que esta só não tenha sido verbalizada ou que houvesse algum bloqueio interno ou externo desses pais impedindo a manifestação dessa imagem. Não se pode excluir também a possibilidade de que realmente eles não estivessem antecipando características do bebê, por alguma razão. Uma delas poderia ser a adoção de uma postura mais tradicional em relação à vivência da paternidade, ditada socialmente, que condiz com preocupações mais de cunho prático e menos de proximidade emocional. Outra razão para a não antecipação do bebê no psiquismo do pai poderia ser a existência de sentimentos ambivalentes relacionados à gestação (Debray, 1988; Szejer \& Stewart, 1997). A ambivalência é um sentimento naturalmente experienciado por mulheres e homens durante a gravidez (Raphael-Leff, 1997), porém os pais parecem ter mais permissão social para expressá-la. Além disso, a ambivalência paterna poderia estar refletindo a ambivalência materna, projetada sobre o companheiro, uma vez que às mães é menos permitido socialmente revelar sentimentos negativos em relação à gestação ou não se mostrar envolvida com a mesma.

Um terceiro motivo para esta condição pode estar relacionado à vivência indireta da gravidez (Parke, 1996; Sherwen, 1986; Szejer \& Stewart, 1997), pois, como os homens não desfrutam da condição biológica de gestar o bebê, podem ter mais dificuldades para se conectar com o mesmo. Essa exclusão pode partir do próprio pai, por acreditar que, em virtude de a mulher estar emprestando seu corpo para gerar o filho do casal, estando por isso mais frágil e vulnerável, merece um lugar de destaque na relação com o bebê. Assim, o pai tenderia a anular seus desejos e sentimentos em prol da gestante, canalizando suas preocupações e investimentos afetivos predominantemente para ela, e menos para o bebê. Por fim, alguns pais poderiam estar ainda se adaptando à nova condição da paternidade, o que dificultaria, para eles, imaginar mais detalhadamente o bebê.
É importante lembrar que, mesmo que alguns pais realmente não tenham construído uma imagem mental do bebê até determinado momento da gestação, não se pode afirmar que eles não estejam envolvidos emocionalmente de alguma maneira que não tenha sido investigada nesse estudo. Por exemplo, uma pesquisa recente (Bornholdt, 2006) mostrou que alguns pais que não pareciam estar próximos aos filhos, por não manifestarem atitudes diretas de cuidado, mostravam-se preocupados com o seu bem-estar mediante a organização financeira da família.

A partir dos resultados sobre a presença ou não de uma imagem mental formada do bebê no psiquismo do pai no período gestacional, fica clara a maneira peculiar de cada pai vivenciar a relação inicial com seu bebê. A paternidade parece estar ainda em processo de redefinição, de modo que alguns pais desempenham seu papel de forma mais tradicional, enquanto outros apresentam uma postura mais ativa, de contato não apenas indireto com o bebê, mas com envolvimento e participação diária. Não se pretende julgar essas diferentes posturas, mas sim conhecê-las, identificando as diferenças na forma de os pais se colocarem diante da gravidez e do bebê. De qualquer modo, não se pode negar que o pai ocupa um lugar diferente da mãe na gestação e tem um acesso também diferente ao bebê, sendo comumente referido na literatura como terceiro na relação. Assim, cabe destacar a natureza e os limites do papel paterno, evitando-se uma equiparação com o papel materno, tido como modelo ideal de vinculação com o bebê. Pais e mães, além da diferença biológica, exercem funções diferentes e essenciais na constituição psíquica da criança, e é assim que deve acontecer para o seu desenvolvimento saudável (Cramer \& Palácio-Espasa, 1993; Stern, 1997).

Tendo em vista que o modelo da relação do pai com o bebê durante a gestação serve de base para a relação pai-filho(a) após o nascimento, é importante um olhar atento sobre a forma como os pais vivenciam a paternidade desde o início da gestação. Assim, reitera-se a necessidade de estudos desta natureza que, cada vez mais, investiguem e aprofundem o entendimento da qualidade das relações iniciais. Com esse intuito, aspectos importantes a serem analisados por estudos futuros seriam as percepções das gestantes sobre o envolvimento do seu parceiro com o bebê. 


\section{Referências}

Anderson, A. M. (1996). Factors influencing the father-infant relationship. Journal of Family Nursing, 2 (3), 306-324.

Bardin, L. (1977). Análise de conteúdo. São Paulo: Edições 70.

Bornholdt, E. (2001). A gravidez do primeiro filho à luz da perspectiva paterna. Dissertação de mestrado não-publicada, Instituto de Psicologia, Pontifícia Universidade Católica do Rio Grande do Sul, Porto Alegre.

Bornholdt, E. (2006). Início de la interacción padre-bebé: perspectiva histórica, política, social y acadêmica. Tesis de doctorado não-publicada, Universidad del Salvador, Buenos Aires, Argentina.

Bradley, E. (2000). Pregnancy and the internal world. In J. Raphael-Leff (Org.), 'Spilt milk' perinatal loss \& breakdown (pp.28-38). London: Institute of Psychoanalysis.

Brazelton, T. B., \& Cramer, B. G. (1992). As primeiras relações. São Paulo: Martins Fontes.

Cabrera, N. J., Tamis-LeMonda, C. S., Bradley, R. H., Hofferth, S. \& Lamb, M. E. (2000). Fatherhood in the twenty-first century. Child Development, 71 (1), 127-136.

Clement, S., Wilson, J., \& Sikorski, J. (1998). Women's experiences of antenatal ultrasound scans. In S. Clement (Org.), Psychological perspectives on pregnancy and childbirth (pp. 7-26). Edinburgh, UK: Churchill Livingstone.

Cramer, B., \& Palacio-Espasa, F. (1993). Técnicas picoterápicas mãe/bebê. Porto Alegre: Artes Médicas.

Debray, R. (1988). Bebês/mães em revolta: tratamentos psicanalíticos conjuntos dos desequilíbrios psicossomáticos precoces. Porto Alegre: Artes Médicas.

Gomes, A. J. S., \& Resende, V. R. (2004). O pai presente: o desvelar da paternidade em uma família contemporânea. Psicologia, Teoria e Pesquisa, 20 (2), 119-125.

Grupo de Interação Social, Desenvolvimento e Psicopatologia. (1998a). Entrevista de contato inicial. Manuscrito não-publicado. Porto Alegre: Instituto de Psicologia, UFRGS.

Grupo de Interação Social, Desenvolvimento e Psicopatologia. (1998b). Entrevista de dados demográficos do casal. Manuscrito não-publicado. Porto Alegre: Instituto de Psicologia, UFRGS.

Grupo de Interação Social, Desenvolvimento e Psicopatologia. (1998c). Entrevista sobre a gestação e as expectativas do futuro pai. Manuscrito não-publicado. Porto Alegre: Instituto de Psicologia, UFRGS.

Hollingshead, A. (1975). The four-factor index of social status. Paper non-published. Yale University.

Klaus, M. H., \& Kennel, J. H. (1993). Pais/bebê: a formação do apego. Porto Alegre: Artes Médicas.

Laville, C., \& Dione, J. (1999). A construção do saber:manual de metodologia de pesquisa em ciências humanas. Porto Alegre: Artes Médicas.

Levandowski, D. C., \& Piccinini, C. A. (2006). Expectativas e sentimentos em relação à paternidade entre adolescentes e adultos. Psicologia: Teoria e Pesquisa, 22 (1), 17-28.
Lewis, C., \& Dessen, M. A. (1999). O pai no contexto familiar. Psicologia: Teoria e Pesquisa, 15 (1), 9-16.

Maldonado, M. T., Dickstein, J., \& Nahoum, J. C. (1997). Nós estamos grávidos. 10a.ed. São Paulo: Saraiva.

Parke, R. (1996). Fatherhood. London: Harvard University Press.

Piccinini, C. A., Gomes, A. G., Moreira, L. E., \& Lopes, R. S. (2004a). Sentimentos e expectativas da gestante em relação ao seu bebê. Psicologia: Teoria e Pesquisa, 20 (3), 233-240.

Piccinini, C. A., Silva, M. R., Gonçalves, T. R., Lopes, R. S., \& Tudge, J. (2004b). O Envolvimento paterno durante a gestação. Psicologia, Reflexão e Crítica, 17 (3), 303-314.

Piontelli, A. (2000). Is there something wrong? The impact of tecnology in pregancy. In J. Raphael-Leff (Org.), 'Spilt milk' perinatalloss \& breakdown (pp.39-52). London: Institut of Psychoanalysis.

Raphael-Leff, J. (1997). Gravidez: a história interior. Porto Alegre: Artes Médicas.

Riesch, S. K., Kuester, L., Brost, D., \& McCarthy, J. G. (1996). Fathers' perceptions of how they were parented. Journal of Community Health Nursing, 13 (1), 13-29.

Shapiro, J. (1987). The expectant father. Psychology Today, $21,(1), 36-42$.

Sherwen, L. N. (1986). Third trimester fantasies of first-time expectant fathers. Maternal Child Nursing Journal, 15 (3), 153-170.

Silveira, P. (1998). O exercício da paternidade. In P. Silveira (Org.), Exercício da paternidade (pp.27-45). Porto Alegre: Artes Médicas.

Slade, A., \& Cohen, L. J. (1996). The process of parenting and the remembrance of things past. Infant Mental Health Journal, 17 (3), 217-238.

Soulé, M. (1987). O filho da cabeça, o filho imaginário. In T. B. Brazelton, B. Cramer, L. Kreisler, R. Schäppi \& M. Soulé (Orgs.), A dinâmica do bebê (pp.132-170). Porto Alegre: Artes Médicas.

Stainton, M. C. (1985). The fetus: a growing member of the family. Family Relations, 34 (3), 321-326.

Stern, D. (1997). A constelação da maternidade: o panorama da psicoterapia pais/bebê. Porto Alegre: Artes Médicas.

Sullivan-Lyons, J. (1998). Men becoming fathers: "Sometimes I wonder how I'll cope". In S. Clement (Org.), Psychological perspectives on pregnancy and chilbirth (pp.227-244). London, UK: Churchill Livingstone.

Szejer, M., \& Stewart, R. (1997). Nove meses na vida da mulher: uma abordagem psicanalítica da gravidez e do nascimento. São Paulo: Casa do Psicólogo.

Recebido em: 25/1/2007

Versão final reapresentada em: 16/8/2007

Aprovado em: 26/11/2007 